\title{
Prevalence and determinants of chronic kidney disease in rural and urban Cameroonians: a cross-sectional study
}

\author{
Francois Folefack Kaze ${ }^{* *}$, Diane Taghin Meto ${ }^{2}$, Marie-Patrice Halle ${ }^{3}$, Jeanne Ngogang $^{2}$ and Andre-Pascal Kengne ${ }^{4}$
}

\begin{abstract}
Background: Chronic kidney disease (CKD) is a global public health problem that disproportionally affects people of African ethnicity. We assessed the prevalence and determinants of CKD and albuminuria in urban and rural adults Cameroonians.

Methods: This was a cross-sectional study of 6-month duration (February to July 2014), conducted in the health district of Dschang (Western Region of Cameroon), using a multistage cluster sampling. All adults diagnosed with albuminuria ( $\geq 30 \mathrm{mg} / \mathrm{g})$ and/or decreased estimated glomerular filtration rate (eGFR) $\left(<60 \mathrm{ml} / \mathrm{min} / 1.73 \mathrm{~m}^{2}\right)$ were re-examined three months later. Logistic regression models were used to relate baseline characteristics with prevalent CKD.
\end{abstract}

Results: We included 439 participants with a mean age of $47 \pm 16.1$ years; with 185 (42.1\%) being men and 119 $(27.1 \%)$ being urban dwellers. There was a high prevalence of hypertension (25.5\%), diabetes (9.8\%), smoking (9.3\%), alcohol consumption (59.7\%), longstanding use of herbal medicine (90.9\%) and street medications (87.5\%), and overweight/obesity (53.3\%) which were predominant in rural area. The prevalence of CKD was $13.2 \%$ overall, $14.1 \%$ in rural and $10.9 \%$ in urban participants. Equivalents figures for CKD stages G3-G4 and albuminuria were $2.5 \%, 1.6 \%$ and $5.0 \%$; and $12.1 \%, 14.1 \%$ and $6.7 \%$ respectively. Existing hypertension and diabetes were associated with all outcomes. Elevated systolic blood pressure and the presence of hypertension and diabetes were the predictors of albuminuria and CKD while urban residence was associated with CKD stages G3-G4.

Conclusion: The prevalence of CKD and albuminuria was high in this population, predominantly in rural area, and driven mostly by the commonest risk factors.

\section{Background}

Chronic kidney disease (CKD) affects about 1 in 10 adults and accounts for millions of premature deaths worldwide [1,2]. Studies have revealed that people of African ethnicity are at higher risk of CKD, which is credited to be 3-4 times more frequent in Africans than in developed countries [3]. Many Sub-Saharan Africa (SSA) countries are going through epidemiological transitions and are confronted with the double burden of communicable and non-communicable diseases including CKD [3-5]. However, the few epidemiological studies conducted in SSA have revealed huge disparities in

\footnotetext{
* Correspondence: francoiskaze@yahoo.fr

${ }^{1}$ Department of Internal Medicine and Specialties, Faculty of Medicine and Biomedical Sciences, University of Yaoundé 1, Yaoundé, Cameroon Full list of author information is available at the end of the article
}

the prevalence of CKD in the adult population, with figures ranging from 1.5 to $38 \%$ depending on methods used to diagnose CKD and population characteristics [6-12]. Furthermore, CKD in SSA tend to affect mostly young adults, with hypertension, chronic glomerulonephritis, diabetes, HIV infection, obesity and herbal medicines use being the main potential contributing factors $[3,5,7,8,10,11]$.

High prevalence of CKD have been reported in Central African countries $[7,8,12]$. However, existing studies have been based on non-optimal definition of CKD using a single measurement; which is at variance with the 2012 KDIGO guidelines recommendations of using at least two measurements three months apart [13]. As such, available studies have likely provided inaccurate estimates of the disease burden. In the absence of data on the epidemiology of 
chronic kidney disease in Cameroon, we undertook this study to establish the prevalence and investigate the determinants of CKD in rural and urban settings in the country.

\section{Methods}

\section{Study design and setting}

This was a cross-sectional study of 6-month duration (February to July 2014), conducted in the health district Dschang in the Western Region of Cameroon (Fig. 1).

\section{Study participants}

\section{Sources of participants}

According to the data from the regional delegation of health for the Western Region of Cameroon, Dschang health district is the largest health district in the region, with an estimated population of 309,285 inhabitants in 2012, distributed across 22 health areas (19 rurals and 3 urbans) (2012 annual activity report of the regional delegation of health for Western Cameroon). Dschang is home to the largest university in the Region and therefore has a cosmopolitan population reflecting the ethnic diversity of the country. The adult population in urban areas comprises students, traders, civil servants and middle income earners from private sectors while farmers are predominant in rural area. This study was approved by the Cameroon National Ethics Committee, and all participants provided a written informed consent before enrolment.

\section{Eligibility criteria}

Eligible participants were adults aged 20 years and above who had been living in the study setting for more than three months. We excluded individuals with serious mental or physical (limb amputation or paralysis) disability, pregnant or breastfeeding women and participants with simultaneous leucocyturia and urine nitrites.

\section{Selection of participants}

We used a multi-level cluster sampling including the health area (first level), the village (second level), the neighbourhood (third level) and the household (fourth level). The sequence below was followed to select the clusters and corresponding health areas. 1) We first assumed the number of clusters needed to be $30 ; 2$ ) We then determined the sampling interval (SI) which corresponded to 10310, by dividing the population of Dschang health district by the number of clusters; 3 ) We determined the first cluster or random number (RN) by selecting the four last numbers of a randomly selected bank note which

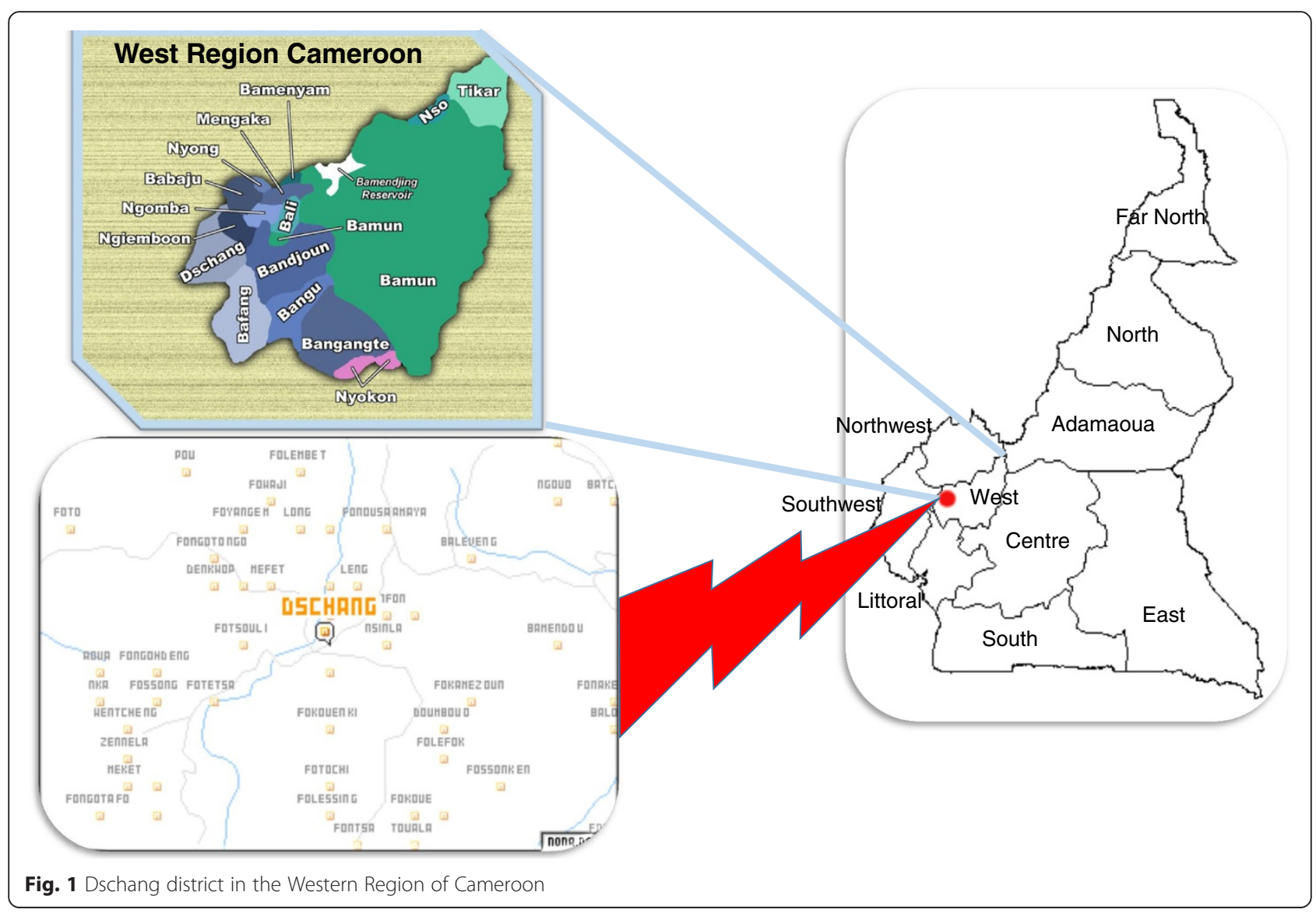


corresponded to 1399 ; 4) We next estimated the cluster number size $\left(C_{(n)}\right)$ from the formula $C_{(n)}=R N+(n-1) * S I$ where $n$ is the cluster number; 5 ) The various health areas (with their corresponding population size) were then sorted in alphabetic order and progressive cumulative population size estimated (see Additional file 1: Table S1); 6) The last step consisted of selecting the health areas. For a health area to be selected, the size of the corresponding cluster number had to be less than the health area population. This action was repeated until the size of the cluster number became superior to the health area population; we then moved to the following health area in the table. The selected health areas and corresponding clusters are presented in Additional file 1: Table S1.

In a selected health area, one village/neighbourhood was randomly drawn when there was more than one regardless of the population size. The starting point was randomly selected from the market, church, health centre or school in the village/neighbourhood. Thereafter, we randomly selected the direction while the side of road was chosen with the aid of coin toss. We entered consecutively in the households where we randomly selected per household a maximum of two adults aged 20 years and above among those who had been living in the household for more than three months. For each household declining to participate, the next household was selected until the total number required for the cluster size was reached. The cluster size ranged between 14 and 15 subjects. In health areas with many clusters, the corresponding villages and/or neighbourhoods were randomly selected as previously described.

\section{Variables of interest}

The main outcome of interest in this study was CKD defined by the persistence after 3 months of albuminuria (Albumin/Creatinine ratio $\geq 30 \mathrm{mg} / \mathrm{g}$ ) and/or decreased estimated glomerular filtration rate (eGFR) $(<60 \mathrm{ml} / \mathrm{min} /$ $1.73 \mathrm{~m}^{2}$ ) according to the K/DIGO guidelines [13]. Exposure variables included demographics (age and gender), self-reported existing conditions (hypertension, diabetes and gout), any hypertension (self-reported or screen-detected [i.e. systolic (or diastolic) blood pressure $\geq 140$ (90)], any diabetes (self-reported or screen-detected [fasting capillary glucose $\geq 126 \mathrm{mg} / \mathrm{dl}$ )], lifestyles (alcohol consumption and smoking), use of nephrotoxins [street medications (western drugs, usually of uncertain origins that are sold in shops and regularly along market streets, instead of pharmacies, and without any control) and herbal medicines], overweight or obesity (body mass index $[\mathrm{BMI}] \geq 25 \mathrm{~kg} / \mathrm{m}^{2}$ ) and blood pressure levels. Potential effect modifier was residency (urban vs. rural).

\section{Data sources and measurement}

Data were collected during household surveys by final year's undergraduate medical students. Demographics, history of existing conditions, lifestyles and data on the use of nephrotoxins were collected during face-to-face interviews with participants. Blood pressure was measured according to the World Health Organization (WHO) guidelines [14] using an automated sphygmomanometer (OMRON HEM705CP, Omron Matsusaka Co, Matsusaka City, Mie-Ken, Japan) on the right arm with participants in a sitting position after $30 \mathrm{~min}$ of rest with a cuff size of $23 \times 12 \mathrm{~cm}$ or larger for obese individuals. Body weight and height were measured three times and their average used in all analyses. For each participant, $3 \mathrm{ml}$ of whole blood was collected from an antecubital vein for serum creatinine and fasting glycemia (after an overnight fast of at least $8 \mathrm{~h}$ ), and mid-stream second morning urine collected for dipstick, creatinine and albumin tests. Fasting glycemia and dipstick tests were done immediately after sample collection. The remaining sample was transported in ice to the Biochemistry Laboratory of the Yaounde University Teaching Hospital for further processing. Urine dipstick tests used the CombiScreen 7SL PLUS 7 test strips (Analyticon Biotechnologies AG, D-35104 Lichentenfeis, Germany). Fasting glycemia was performed using One Touch Ultra ${ }^{\oplus}$ easy reader ${ }^{\circledR}$ (LifeScan Europe, Cilag GmbH International, Zug, Switzerland). Serum and urinary creatinine were measured with a kinetic modification of the Jaffé reaction using Human visual spectrophotometer (Human Gesellschaft, Biochemica und Diagnostica mbH, Wiesbaden, Germany) and Beckman creatinine analyzer (Beckman CX systems instruments, Anaheim, CA, USA) while urinary albumin was measured using pyrogallol red-molybdate complex with Teco diagnostics tests (Teco Diagnostics, Anaheim, CA, USA). For any participant with positive dipstick [proteine ( $\geq$ trace), blood, leucocytes), albu$\mathrm{min} /$ creatinine ratio $(\mathrm{ACR}) \geq 30 \mathrm{mg} / \mathrm{g}$ and fasting glycemia of at least $126 \mathrm{mg} / \mathrm{dl}$ (for unknown diabetes), another test was performed 2 to 3 weeks after to confirm the results. In participants with estimated glomerular filtration rate $($ eGFR $)<60 \mathrm{ml} / \mathrm{min} / 1.73 \mathrm{~m}^{2}$ according to the MDRD formula and/or urinary albu$\mathrm{min} /$ creatinine ratio $(\mathrm{ACR}) \geq 30 \mathrm{mg} / \mathrm{g}$, the chronicity was confirmed on another sample 3 months later.

\section{Definitions and calculations}

Estimated glomerular filtration rate (eGFR, $\mathrm{ml} / \mathrm{min}$ ) corresponded to creatinine clearance. For the main analyses, eGFR was based on the four-variable MDRD (Modification of Diet in Renal Disease) study equation; however, for comparison purpose of the baseline estimates, we also derived the eGFR from the Cockcroft-Gault (CG) formula and the CKD-EPI (Chronic Kidney Disease Epidemiology Collaboration) equations [15-17]. 24-h albuminuria was estimated from Albumin/Creatinine ratio $(\mathrm{mg} / \mathrm{g})$. BMI was estimated as weight $(\mathrm{kg}) /$ height $(\mathrm{m})$ *height $(\mathrm{m})$. 


\section{Study size}

By considering a $10 \%$ prevalence $(\mathrm{P})$ of CKD in adults [1], a precision (I) of $2 \%$, a correction factor (K) of 2 for the cluster effect, a $95 \%$ confidence interval, the minimal sample size $(\mathrm{N})$ required was 432 subjects using the following formula $N=\left[(\mathrm{Z} \alpha / 2)^{2} \mathrm{PQ} / \mathrm{I}^{2}\right] \times \mathrm{K}$.

\section{Handling of quantitative variables}

Age was treated as continuous variable in all analysis while blood pressure, while other quantitative variables were treated both as continuous and categorical variables, based on clinically meaningful stratification. Hypertension was defined as a systolic (SBP) $\geq 140 \mathrm{mmHg}$ and/or a diastolic blood pressure (DBP) $\geq 90 \mathrm{mmHg}$ or use of blood pressure lowering medications. Diabetes mellitus was defined as repeated fasting glycemia $\geq 126 \mathrm{mg} / \mathrm{dl}$ or use of glucose control agents. A BMI $>25 \mathrm{~kg} / \mathrm{m}^{2}$ was used to define overweight and obesity. CKD was classified based on GFR and albuminuria categories. GFR categories of CKD included: G1 (eGFR $\geq 90$ ); G2 (eGFR 60-89); G3a (eGFR 45-59); G3b (eGFR 30-44); G4 (eGFR 15-29) and G5 $(\mathrm{eGFR}<15)$. Albuminuria categories of CKD were: A1 (<30 mg/g); A2 (30-300 mg/g) and A3 (>300 mg/g). The following formula was used to convert serum creatinine from Jaffe reaction $\left(\mathrm{SCr}_{\mathrm{Jaffe}}\right)$ to standardized serum creatinine $\left(\mathrm{SCr}_{\text {Standardized }}\right)$ for use in MDRD and CKD-EPI formulas: $\mathrm{SCr}_{\text {Standardized }}=0.95 * \mathrm{SCr}_{\text {Jaffe }}-0.10$ [18].

\section{Statistical analysis}

Data analysis used SAS/STAT v9.1 software and the survey analysis procedures ('proc surveymeans', 'proc surveyreg' and 'proc surveylogistic') to account for the multilevel sampling design of the study. We have reported the results as means, counts and percentages and the accompanying $95 \%$ confidence intervals. The sampling error was estimated with the use of the Taylor expansion method. Age and sex adjusted logistic regression models were used to investigate the predictors of CKD, CKD stages G3-G4 and albuminuria. A p-value $<0.05$ was used to indicate statistically significant results. For the main analyses, prevalence and determinants of CKD are based on MDRD derived eGFR. In secondary analyses however, we have also estimated GFR and staged kidney function using the Cockroft-Gault and CKD-EPI equations.

\section{Results}

\section{Baseline characteristics of the study population}

A total of 238 households were included in the survey from which 439 subjects (two participants from 201 households and one participant from the remaining) participated in the study. Eleven (2.5\%) participants from seven $(2.9 \%)$ households refused to participate. These households were replaced as described above. The reasons for non-participation were fear (3 participants, 2 households), absence from home after several visits (2 participants, 2 households) and lack of time due to work constraints (6 participants, 3 households).

We included 439 participants aged $47 \pm 16.1$ years, with 185 (42.1\%) being men and 119 (27.1 \%) being urban dweller. In all, 120 (27.3\%) participants had renal abnormalities requiring repeated tests to confirm the chronicity, including $73(60.8 \%)$ with only albuminuria (ACR $\geq 30 \mathrm{mg} / \mathrm{g}), 34$ (28.3\%) with only decreased eGFR $\left(<60 \mathrm{ml} / \mathrm{min} / 1.73 \mathrm{~m}^{2}\right)$ and $13(10.8 \%)$ with both. The chronicity confirmation test was not performed in 6 (5.3\%) participants including 1 (1.4\%) for albuminuria, 3 (10.3\%) for decreased eGFR and 2 (18.2 \%) for both. Reasons for not performing the tests were death (one case) and hospitalisation (5 cases) in other cities for medical care. They were all considered as having negative confirmation tests.

As presented in Table 1, we noticed a high proportion of participants who were unaware of their status for renal disease (80.9\%), hypertension (33\%), diabetes (42.6\%) and gout (56.3\%). There was also a high prevalence of CKD related risk factors in this setting including hypertension (25.5\%), diabetes (9.8\%), smoking (9.3\%), alcohol consumption (59.7\%), longstanding use of herbal medicines (90.9\%) and street medications (87.5\%), and overweight/obesity (53.3\%). This population presented a high prevalence of dipstick proteinuria (19.6\%) and decreased eGFR at $10.7 \%$ based on the MDRD equation, Table 2.

Compared with their urban counterparts, rural participants were older (51.0 vs. 36.5 years, $p<0.001)$ and less aware of their status for renal disease, hypertension, diabetes and gout (all $p<0.001$ ), Table 1 . Furthermore, they included higher proportion of alcohol drinkers, longstanding users of street and herbal medicine, and had elevated SBP and waist girth, and higher prevalence of hypertension and albuminuria (all $p \leq 0.021$ ), Tables 1 and 2 . The prevalence of combined albuminuria and/or decreased MDRD-based eGFR was 30 \% (95 \% CI: 24.3-46.7) in rural and $20.2 \%(8.3-32.0)$ in urban areas $(\mathrm{p}=0.162)$, Table 2. There were suggestions that urban vs. rural variations in the levels of some characteristics occurred in differential ways between men and women. This was the case for age, tobacco use, alcohol use, body mass index, eGFR and prevalent CKD (all $p<0.037$ for sex*residence interactions), Tables 1 and 2 .

\section{Prevalence and correlates of albuminuria and chronic kidney disease}

As presented in Table 3, the prevalence of albuminuria was $12.1 \%(n=53)$ overall, $14.1 \%(n=45)$ in rural and $6.7 \%$ $(n=8)$ in urban participants $(p=0.047)$. Compared with their non-albuminuric counterparts, participants with albuminuria had higher prevalence of existing hypertension 
Table 1 Baseline clinical characteristics by sex and urban/rural location

\begin{tabular}{|c|c|c|c|c|c|}
\hline Characteristics & Overall & Rural & Urban & $\mathrm{p}$ & p sex*residence \\
\hline $\mathrm{n}(\%)$ & $439(100)$ & $320(72.9)$ & $119(27.1)$ & & \\
\hline Mean age, years $(95 \% \mathrm{Cl})$ & $47.0(42.5-51.6)$ & $51.0(49.1-52.9)$ & $36.5(32.6-40.3)$ & $<0.0001$ & 0.007 \\
\hline Men, n; \% (95 \% Cl) & $185 ; 42.1(35.6-48.7)$ & $127 ; 39.7(33.0-46.4)$ & $58 ; 48.7(37.3-60.2)$ & 0.154 & NA \\
\hline History of renal disease, n; \% (95 \% Cl) & & & & $<0.0001$ & 0.640 \\
\hline Yes & $1 ; 0.2(0.0-0.7)$ & 0 & $1 ; 0.8(0.0-1.7)$ & & \\
\hline No & $83 ; 18.9(0.0-38.1)$ & $12 ; 3.8(1.9-5.6)$ & $71 ; 59.7(38.7-80.6)$ & & \\
\hline Don't know & $355 ; 80.9(61.3-100.0)$ & $308 ; 96.2(94.4-98.1)$ & $47 ; 39.5(17.8-61.1)$ & & \\
\hline History of hypertension, n; \% (95 \% Cl) & & & & $<0.0001$ & 0.712 \\
\hline Yes & $47 ; 10.7(8.3-13.1)$ & $33 ; 10.3(7.3-13.3)$ & $14 ; 11.8(9.7-13.8)$ & & \\
\hline No & $247 ; 56.3(46.5-66.1)$ & $148 ; 46.3(43.9-48.5)$ & $99 ; 83.2(76.6-89.7)$ & & \\
\hline Don't know & $145 ; 33.0(22.4-43.6)$ & $139 ; 43.4(40.4-46.4)$ & $6 ; 5.0(0.0-11.8)$ & & \\
\hline History of diabetes, n; \% (95 \% Cl) & & & & $<0.001$ & 0.835 \\
\hline Yes & $26 ; 5.9(2.7-9.1)$ & $23 ; 7.2(3.8-10.5)$ & $3 ; 2.5(0.0-6.6)$ & & \\
\hline No & $226 ; 51.5(38.3-64.7)$ & $122 ; 38.1(35.0-41.3)$ & $104 ; 87.4(81.2-93.6)$ & & \\
\hline Don't know & $187 ; 42.6(31.1-54.1)$ & $175 ; 54.7(51.6-57.8)$ & $12 ; 10.1(6.0-14.2)$ & & \\
\hline History of gout, n; \% (95 \% Cl) & & & & $<0.001$ & 0.063 \\
\hline Yes & $5 ; 1.1(0.6-1.7)$ & $4 ; 1.3(0.6-1.9)$ & $1 ; 0.8(0.0-1.7)$ & & \\
\hline No & $187 ; 42.6(26.6-58.6)$ & $84 ; 26.3(22.8-29.7)$ & $103 ; 86.6(80.5-92.6)$ & & \\
\hline Don't know & $247 ; 56.3(40.2-72.3)$ & $232 ; 72.5(69.0-76.0)$ & $15 ; 12.6(6.2-19.0)$ & & \\
\hline Tobacco use currently or formerly, n; \% (95 \% Cl) & $41 ; 9.3(7.5-11.2)$ & $34 ; 10.6(8.5-12.7)$ & $7 ; 5.9(4.5-7.3)$ & $<0.0001$ & 0.009 \\
\hline Alcohol use currently or formerly, n; \% (95 \% Cl) & $262 ; 59.7(51.3-68.1)$ & $211 ; 65.9(60.7-71.1)$ & $51 ; 42.9(27.6-58.1)$ & 0.003 & 0.001 \\
\hline Longstanding use of herbal medicine, n; \% (95 \% Cl) & $399 ; 90.9(83.8-97.9)$ & $312 ; 97.5(96.1-98.9)$ & $87 ; 73.1(65.6-80.6)$ & $<0.0001$ & 0.090 \\
\hline Longstanding use of street medications, n; \% (95 \% Cl) & $384 ; 87.5(77.3-97.7)$ & 306; 95.6 (93.9-97.4) & $78 ; 65.5(51.6-79.4)$ & $<0.0001$ & 0.064 \\
\hline Mean systolic blood pressure, mmHg (95 \% Cl) & $119.5(117.0-122.1)$ & $121.2(119.5-122.9)$ & $115.0(111.6-118.5)$ & 0.015 & 0.163 \\
\hline Mean diastolic blood pressure, mmHg (95 \% Cl) & $77.9(77.0-78.9)$ & $78.1(77.0-79.3)$ & $77.4(76.0-78.8)$ & 0.543 & 0.253 \\
\hline Any hypertension, n (\%) & $112 ; 25.5(22.3-28.7)$ & $92 ; 28.8(25.7-31.8)$ & $20 ; 16.8(13.0-20.6)$ & $<0.0001$ & 0.077 \\
\hline Mean body mass index, $\mathrm{kg} / \mathrm{m}^{2}$ (95 \% Cl) & $26.0(25.7-26.4)$ & $26.0(25.6-26.4)$ & $26.2(25.5-26.8)$ & 0.711 & 0.004 \\
\hline $\mathrm{BMI} \geq 25, \mathrm{n} ; \%(95 \% \mathrm{Cl})$ & $234 ; 53.3(49.5-57.1)$ & $169 ; 52.8(49.5-56.1)$ & $65 ; 54.6(45.6-63.6)$ & 0.696 & 0.102 \\
\hline Mean waist girth, cm (95 \% Cl) & $88.4(87.2-89.7)$ & $89.2(88.0-90.4)$ & $86.3(84.8-87.9)$ & 0.021 & 0.277 \\
\hline Mean fasting glycemia, g/l (95 \% Cl) & $0.92(0.88-0.96)$ & $0.93(0.88-0.97)$ & $0.91(0.87-0.95)$ & 0.539 & 0.387 \\
\hline Any diabetes, n; \% (95 \% Cl) & $43 ; 9.8(6.6-13.0)$ & $34 ; 10.6(7.2-14.0)$ & $9 ; 7.6(2.1-13.1)$ & 0.370 & 0.976 \\
\hline
\end{tabular}

$95 \% \mathrm{Cl} 95 \%$ confidence intervals

$(p<0.0001)$, diabetes $(p<0.003)$, gout $(p=0.0002)$ and longstanding use of herbal medicine $(p=0.0001)$, higher SBP $(\mathrm{p}=0.019)$, and higher prevalence of any hypertension $(p=0.0001)$ and diabetes $(p=0.008)$. The prevalence of CKD was $13.2 \%$ with $2.5 \%$ at stages G3G4, Table 3. Equivalents figures were $14.1 \%$ and $1.6 \%$ in rural, and $10.9 \%$ and $5.0 \%$ in urban participants. CKD was associated with history of hypertension $(p=0.001)$, diabetes $(p=0.017)$ and gout $(p=0.009)$, herbal medicines $(p<0.0001)$ and street medications $(p=0.007)$ use, any diabetes $(p=0.017)$ and hypertension $(p<0.0001)$, while stages G3-G4 of CKD were associated with female sex $(p<0.0001)$, tobacco use $(p<0.0001)$, and herbal medicines $(p<0.0001)$ and street medications $(p<0.0001)$ use, Table 3. In males vs. female comparisons, the prevalence of albuminuria was $10.3 \%$ and $13.4 \%$ respectively. Equivalents figures were $10.3 \%$ and $15.3 \%$ for CKD, and $0 \%$ and $4.3 \%$ for stages G3-G4 of CKD.

\section{Predictors of albuminuria and chronic kidney disease in age, sex and residency adjusted logistic regressions}

Existing hypertension and diabetes were consistently and positively associated with higher risk of all outcomes with however, borderline association between hypertension and stages G3-G4 CKD $(p=0.056)$, Table 4. Elevated SBP and the presence of hypertension and diabetes were the predictors of albuminuria and CKD. Rural residence was negatively and consistently associated with the presence of 
Table 2 Baseline kidney function test and urine profile by location

\begin{tabular}{|c|c|c|c|c|c|}
\hline Characteristics & Overall & Rural & Urban & $\mathrm{p}$ & p sex residence \\
\hline n (\%) & $439(100)$ & $320(72.9)$ & $119(27.1)$ & & \\
\hline \multicolumn{6}{|l|}{ Dipstick abnormalities, n; \% (95 \% Cl) } \\
\hline Proteinuria & $86 ; 19.6(13.5-25.6)$ & $76 ; 23.8(18.5-29.0)$ & $10 ; 8.4(3.3-13.5)$ & 0.0005 & 0.155 \\
\hline Leucocyturia & $22 ; 5.0(2.4-7.6)$ & $10 ; 3.1(1.6-4.7)$ & $12 ; 10.1(0.0-20.1)$ & 0.034 & 0.807 \\
\hline Hematuria & $2 ; 0.5(0.0-1.1)$ & 0 & $2 ; 1.7(0.2-3.2)$ & $<0.0001$ & 0.984 \\
\hline Albuminuria, mg/g, n; \% (95% Cl) & & & & 0.0004 & 0.148 \\
\hline$<30$ & $353 ; 80.4(74.3-86.5)$ & $244 ; 76.3(71.0-81.5)$ & $109 ; 91.6(86.5-96.7)$ & & \\
\hline $30-300$ & $70 ; 15.9(10.0-21.8)$ & $64 ; 20.0(15.6-24.3)$ & $6 ; 5.0(0.0-11.1)$ & & \\
\hline$>300$ & $16 ; 3.6(2.1-5.2)$ & $12 ; 3.8(1.9-5.6)$ & $4 ; 3.4(1.1-5.6)$ & & \\
\hline Mean serum creatinine, mg/l (95 \% Cl) & $10.6(10.0-11.2)$ & $10.3 ; 4.9(9.6-10.9)$ & $11.6 ; 3.9(10.5-12.8)$ & 0.065 & 0.037 \\
\hline \multicolumn{6}{|l|}{ Mean eGFR, ml/min (95% Cl) } \\
\hline MDRD & 109.5 (104.0-115.0) & $110.9 ; 38.2(105.2-116.5)$ & $105.8 ; 48.1(91.7-119.8)$ & 0.522 & 0.0005 \\
\hline CKD-EPI & $106.4(101.3-111.5)$ & 107.2; $30.1(102.6-111.8)$ & 104.2; $38.6(90.1-118.3)$ & 0.622 & 0.0003 \\
\hline CG & $89.1(83.2-95.0)$ & $88.2 ; 35.5(83.1-93.2)$ & $91.8 ; 35.4(78.4-105.1)$ & 0.691 & 0.0002 \\
\hline \multicolumn{6}{|l|}{ Stages of kidney function by eGFR, n; \% (95 \% Cl) } \\
\hline $\operatorname{MDRD}\left(\mathrm{ml} / \mathrm{min} / 1.73 \mathrm{~m}^{2}\right)>90$ & $303 ; 69.0(63.3-74.7)$ & $238 ; 74.4(70.4-78.3)$ & $65 ; 54.6(38.3-70.9)$ & 0.2681 & 0.711 \\
\hline $60-90$ & $89 ; 20.3(15.0-25.5)$ & $53 ; 16.6(13.1-20.0)$ & $36 ; 30.3(16.7-43.8)$ & & \\
\hline$<60$ & $47 ; 10.7(5.4-16.0)$ & $29 ; 9.1(3.0-15.1)$ & $18 ; 15.1(4.5-25.8)$ & & \\
\hline $\mathrm{CG}(\mathrm{ml} / \mathrm{min})>90$ & $197 ; 44.9(39.7-50.1)$ & $142 ; 44.4(40.6-48.2)$ & $55 ; 46.2(32.2-60.2)$ & 0.757 & 0.090 \\
\hline $60-90$ & $146 ; 33.3(30.6-35.9)$ & $106 ; 33.1(29.9-36.3)$ & $40 ; 33.6(29.5-37.7)$ & & \\
\hline$<60$ & $96 ; 21.9(16.3-27.4)$ & $72 ; 22.5(18.2-26.8)$ & $24 ; 20.2(5.7-34.6)$ & & \\
\hline CKD-EPI $\left(\mathrm{ml} / \mathrm{min} / 1.73 \mathrm{~m}^{2}\right)>90$ & $309 ; 70.4(64.7-76.0)$ & $243 ; 75.9(72.3-79.6)$ & $66 ; 55.5(38.4-72.5)$ & 0.242 & 0.543 \\
\hline $60-90$ & $82 ; 18.7(13.6-23.7)$ & $48 ; 15.0(11.9-18.1)$ & $34 ; 28.6(15.2-41.9)$ & & \\
\hline$<60$ & $48 ; 10.9(5.4-16.4)$ & $29 ; 9.1(3.0-15.1)$ & $19 ; 16.0(3.9-28.0)$ & & \\
\hline Albuminuria $(\geq 30)$ and/or eGFR $(<60)$ MDRD & $120 ; 27.3(20.6-34.5)$ & $96 ; 30.0(24.3-35.7)$ & $24 ; 20.2(8.3-32.0)$ & 0.162 & $<0.0001$ \\
\hline Albuminuria $(\geq 30)$ and/or eGFR $(<60)$ CG & $157 ; 35.8(27.3-44.2)$ & $129 ; 40.3(34.5-46.1)$ & $28 ; 23.5(7.8-39.3)$ & 0.072 & 0.022 \\
\hline Albuminuria( $\geq 30$ ) and/or eGFR(<60)CKD-EPI & $121 ; 27.6(20.6-34.5)$ & $96 ; 30.0(24.3-35.7)$ & $25 ; 21.0(7.5-34.6)$ & 0.252 & $<0.0001$ \\
\hline
\end{tabular}

CG Cockroft-Gault, CKD-EPI Chronic kidney disease epidemiology collaboration, eGFR Estimated glomerular filtration rate, MDRD Modification of Diet in Renal Disease, $95 \%$ Cl $95 \%$ confidence intervals

stages G3-G4 CKD while age and sex did not affect any of the outcomes, Table 4.

\section{Secondary analyses}

The staging of kidney function and the prevalence of any Albuminuria $(\geq 30 \mathrm{mg} / \mathrm{g})$ and/or eGFR $(<60 \mathrm{ml} / \mathrm{min} /$ $1.73 \mathrm{~m}^{2}$ ) at baseline based on Cockroft-Gault (CG) and CKD-EPI equations are shown in Table 2. Mean eGFR was lower based on CG and higher based on CKD-EPI, consistently in urban and rural areas, with significant sex differential in the distribution of eGFR across areas (both $p \leq 0.0003$ for sex*residency interactions). The overall prevalence of decreased eGFR ( $<60 \mathrm{ml} / \mathrm{min})$ was 21.9 \% (95 \% CI: 16.3-27.4) based on CG and $10.9 \%$ (5.4-16.4) based on CKD-EPI, similarly in urban and rural areas (both $p \geq 0.242$ ), with no evidence of sex residence interactions (both $p \geq 0.09$ ). The prevalence of the combined albuminuria and/or decreased eGFR was $35.8 \%$
(27.3-44.2 \%) based on CG, and $27.6 \%$ (20.6-34.5) based on CKD-EPI. There was no rural vs. urban differences (both $p \geq 0.072$ ); but there was evidence of significant interactions between gender and residence for both prevalence (both $p \leq 0.022$ for sex*residence interaction), Tables 2 .

\section{Discussion}

This study revealed an overall high prevalence of CKD including albuminuria and stages G3-G4 as well as their related risk factors in this population, predominantly in the rural area, regardless the age and sex of participants. CKD and albuminuria were associated with history of hypertension and diabetes, elevated SBP and the presence of hypertension and diabetes, whereas existing diabetes and hypertension, and urban residency predicted the presence of stages G3-G4 CKD.

The high prevalence of CKD observed in this population has been reported in similar proportions in previous 
Table 3 Characteristics according to the presence/absence of chronic kidney disease with glomerular filtration rate and albuminuria categories

\begin{tabular}{|c|c|c|c|c|c|c|c|c|c|}
\hline \multirow[t]{2}{*}{ Variables } & \multicolumn{3}{|l|}{ CKD } & \multicolumn{3}{|l|}{ GFR based CKD stages } & \multicolumn{3}{|c|}{ Albuminuria based CKD stages } \\
\hline & No & Yes & $\mathrm{p}$ & G1-G2 & G3-G4 & $\mathrm{p}$ & $\mathrm{A} 1$ & $\mathrm{~A} 2-\mathrm{A} 3$ & $\mathrm{p}$ \\
\hline n (\%) & $381(86.8)$ & $58(13.2)$ & & $428(97.5)$ & $11(2.5)$ & & $386(87.9)$ & $53(12.1)$ & \\
\hline Sex (Men), n; \% (95% Cl) & $166 ; 43.6(36.7-50.5)$ & $19 ; 32.8(20.5-45.0)$ & 0.094 & $185 ; 43.2(36.9-49.5)$ & 0 & $<0.0001$ & $166(36.2-49.8)$ & $19 ; 35.8(23.7-48.0)$ & 0.230 \\
\hline Rural residence, n; \% (95% Cl) & $275 ; 72.2(47.8-96.6)$ & $45 ; 77.6(56.7-98.5)$ & 0.432 & $315 ; 73.6(50.2-97.0)$ & $5 ; 45.5(0.0-92.3)$ & 0.077 & $275 ; 71.2(46.5-96.0)$ & $45 ; 84.9$ (70.81-99.0) & 0.047 \\
\hline Mean age, years (95 \% Cl) & $46.5(41.5-51.5)$ & $50.2(46.7-53.8)$ & 0.191 & $46.9(42.4-51.5)$ & $50.6(40.9-60.3)$ & 0.413 & $46.5(41.5-51.5)$ & $50.7(46.8-54.5)$ & 0.193 \\
\hline History of hypertension, n; \% (95 \% Cl) & & & 0.001 & & & 0.766 & & & $<0.0001$ \\
\hline Yes & $34 ; 8.9(6.1-11.7)$ & $13 ; 22.4(12.7-32.1)$ & & $42 ; 9.8(7.4-12.2)$ & $5 ; 45.5(16.6-74.3)$ & & $35 ; 9.1(6.4-11.7)$ & $12 ; 22.6(12.2-33.1)$ & \\
\hline No & $226 ; 59.3(49.7-69.0)$ & $21 ; 36.2(26.3-46.1)$ & & $242 ; 56.5(47.0-66.1)$ & $5 ; 45.5(17.7-73.2)$ & & 230; $59.6(49.6-69.5)$ & $17 ; 32.1(24.0-40.1)$ & \\
\hline Don't know & $121 ; 31.8(21.1-42.4)$ & $24 ; 41.4(27.1-55.6)$ & & $144 ; 33.6(23.0-44.3)$ & $1 ; 9.1(0.0-28.2)$ & & $121 ; 31.3(20.6-42.1)$ & 24; $45.3(31.4-59.1)$ & \\
\hline History of diabetes, n; \% (95 \% Cl) & & & 0.017 & & & 0.662 & & & 0.003 \\
\hline Yes & $16 ; 4.2(0.9-7.5)$ & $10 ; 17.2(6.5-27.9)$ & & $23 ; 5.4(2.4-8.4)$ & $3 ; 27.3(0.0-60.1)$ & & $16 ; 4.1(0.8-7.5)$ & $10 ; 18.9(8.0-29.7)$ & \\
\hline No & $206 ; 54.1(40.8-67.3)$ & $20 ; 48.3(19.1-49.8)$ & & $219 ; 51.2(38.2-64.1)$ & 7; $63.6(28.4-98.8)$ & & $211 ; 54.7(41.1-68.2)$ & $15 ; 28.3(17.1-39.5)$ & \\
\hline Don't know & $159 ; 41.7(29.6-53.9)$ & $28 ; 48.3(34.6-61.9)$ & & $186 ; 43.5(31.9-55.0)$ & $1 ; 9.1(0.0-28.2)$ & & $159 ; 41.2(28.8-53.6)$ & $28 ; 52.8(40.1-65.6)$ & \\
\hline History of gout, n; \% (95 \% Cl) & & & 0.009 & & & 0.566 & & & 0.0002 \\
\hline Yes & $4 ; 1.0(0.4-1.7)$ & $1 ; 1.7(1.0-2.4)$ & & $5 ; 1.2(0.6-1.7)$ & 0 & & $4 ; 1.0(0.4-1.7)$ & $1 ; 1.9(1.2-2.6)$ & \\
\hline No & $169 ; 44.4(28.2-60.5)$ & $18 ; 31.0(14.9-47.2)$ & & $181 ; 42.3(26.6-58.0)$ & $6 ; 54.5(7.7-100)$ & & $174 ; 45.1(28.5-61.6)$ & $13 ; 24.5(12.9-36.2)$ & \\
\hline Don't know & $208 ; 54.6(38.2-71.0)$ & $39 ; 67.2(51.4-83.1)$ & & $242 ; 56.5(40.7-72.3)$ & $5 ; 45.5(0.0-92.3)$ & & $208 ; 53.9(37.2-70.6)$ & $39 ; 73.6(62.1-85.1)$ & \\
\hline Tobacco use, n; \% (95 \% Cl) & $38 ; 10.0(8.0-12.0)$ & $3 ; 5.2(0.8-9.5)$ & 0.071 & $41 ; 9.6(7.7-11.5)$ & 0 & $<0.0001$ & $38 ; 9.8(7.8-11.9)$ & $3 ; 5.7(1.0-10.3)$ & 0.129 \\
\hline Alcohol use, n; \% (95 \% Cl) & $231 ; 60.6(51.5-69.8)$ & $31 ; 53.4(39.5-67.4)$ & 0.310 & $259 ; 60.5(51.9-69.1)$ & $3 ; 27.3(0.0-57.0)$ & 0.068 & $234 ; 60.6(51.3-70.0)$ & $28 ; 52.8(38.6-67.1)$ & 0.300 \\
\hline $\begin{array}{l}\text { Longstanding use of herbal } \\
\text { medicine, n; \% (95\% Cl) }\end{array}$ & $341 ; 89.5(81.5-97.5)$ & $58 ; 100(100-100)$ & $<0.0001$ & 388; 90.7 (83.4-97.9) & $11 ; 100(100-100)$ & $<0.0001$ & $346 ; 89.6(81.8-97.4)$ & $53 ; 100(100-100)$ & $<0.0001$ \\
\hline $\begin{array}{l}\text { Longstanding use of street } \\
\text { medications, n; } \% \text { (95\% Cl) }\end{array}$ & $330 ; 86.6(81.5-97.5)$ & $54 ; 93.1(85.7-100.0)$ & 0.007 & $373 ; 87.1(76.7-97.6)$ & $11 ; 100(100-100)$ & $<0.0001$ & $335 ; 86.8(76.4-97.2)$ & 49; $92.5(84.1-100.0)$ & 0.025 \\
\hline $\begin{array}{l}\text { Mean systolic blood pressure, } \\
\mathrm{mmHg}(95 \% \mathrm{Cl})\end{array}$ & $118.6(116.6-120.6)$ & $125.6(118.3-133.0)$ & 0.053 & $119.3(117.1-121.5)$ & $128.3(103.0-153.5)$ & 0.457 & $118.5(116.2-120.7)$ & $127.2(120.7-133.7)$ & 0.019 \\
\hline $\begin{array}{l}\text { Mean diastolic blood pressure, } \\
\mathrm{mmHg}(95 \% \mathrm{Cl})\end{array}$ & $77.7(76.8-78.5)$ & $79.8(76.0-83.5)$ & 0.294 & $77.9(76.8-78.9)$ & $81.5(70.4-92.6)$ & 0.511 & $77.6(76.8-78.4)$ & $80.3(76.8-83.8)$ & 0.164 \\
\hline Any hypertension, n; \% (95% Cl) & $89 ; 23.4(19.7-27.0)$ & 23; $39.7(31.9-47.4)$ & $<0.0001$ & $107 ; 25.0(21.7-28.3)$ & $5 ; 45.5(16.6-74.3)$ & 0.107 & 90; $23.3(19.6-27.0)$ & $22 ; 41.5(32.7-50.3)$ & $<0.0001$ \\
\hline Body mass index $\geq 25, \mathrm{n} ; \%(95 \% \mathrm{Cl})$ & $200 ; 52.5(48.7-56.3)$ & $34 ; 58.6(48.1-69.2)$ & 0.196 & $227 ; 53.0(48.8-57.3)$ & $7 ; 63.6(39.8-100)$ & 0.526 & $204 ; 52.8(49.3-56.4)$ & 30; $56.6(46.2-67.0)$ & 0.374 \\
\hline Mean fasting glycemia, g/l (SD) & $0.91(0.87-0.94)$ & $1.02(0.86-1.18)$ & 0.167 & $0.91(0.88-0.95)$ & $1.25(0.73-1.76)$ & 0.200 & $0.91(0.87-0.94)$ & $1.02(0.85-1.20)$ & 0.191 \\
\hline Any diabetes, n; \% (95 \% Cl) & $32 ; 8.4(4.7-12.1)$ & $11 ; 19.0(8.9-29.0)$ & 0.017 & $40 ; 9.3(6.2-12.5)$ & $3 ; 27.3(0.0-0.60)$ & 0.102 & $32 ; 8.3(4.6-12.0)$ & $11 ; 20.8(10.3-31.2)$ & 0.008 \\
\hline
\end{tabular}

CKD Chronic kidney disease, GFR glomerular filtration rate (GFR); $95 \%$ Cl $95 \%$ confidence intervals 
Table 4 Predictors of chronic kidney disease and albuminuria in age, sex and residence adjusted logistic regressions

\begin{tabular}{|c|c|c|c|c|c|c|}
\hline \multirow[t]{2}{*}{ Variables } & \multicolumn{2}{|l|}{ CKD } & \multicolumn{2}{|l|}{ CKD Stages G3-G4 } & \multicolumn{2}{|l|}{ Albuminuria } \\
\hline & OR $(95 \% \mathrm{Cl})$ & $p$ & OR $(95 \%$ Cl) & $p$ & OR $(95 \%$ Cl) & $p$ \\
\hline Sex (men) & $0.63(0.36-1.08)$ & 0.095 & $<0.001(<0.001-<0.001)$ & $<0.0001$ & $0.76(0.46-1.25)$ & 0.283 \\
\hline Residence (rural) & $1.06(0.52-2.16)$ & 0.880 & $0.16(0.04-0.69)$ & 0.008 & $1.92(1.06-3.48)$ & 0.031 \\
\hline Age, per years & $1.01(0.99-1.03)$ & 0.178 & $1.03(1.00-1.07)$ & 0.066 & $1.01(0.99-1.03)$ & 0.293 \\
\hline History of hypertension & & $<0.0001$ & & 0.056 & & $<0.0001$ \\
\hline No & 1 (reference) & & 1 (reference) & & 1 (reference) & \\
\hline Yes & $3.95(2.09-7.46)$ & & $4.74(0.84-26.58)$ & & $4.67(2.63-8.29)$ & \\
\hline Don't know & $2.16(1.29-3.63)$ & & $0.50(0.03-8.66)$ & & $2.38(1.40-4.03)$ & \\
\hline History of diabetes & & $<0.0001$ & & 0.004 & & $<0.0001$ \\
\hline No & 1 (reference) & & 1 (reference) & & 1 (reference) & \\
\hline Yes & $6.64(2.63-16.75)$ & & $4.49(1.55-13.03)$ & & $8.13(3.17-20.84)$ & \\
\hline Don't know & $1.89(1.09-3.26)$ & & $0.17(0.01-3.11)$ & & $2.25(1.26-4.01)$ & \\
\hline History of gout & & 0.131 & & $<0.0001$ & & 0.064 \\
\hline No & 1 (reference) & & 1 (reference) & & 1 (reference) & \\
\hline Yes & $2.58(0.96-6.94)$ & & $<0.001(<0.001-<0.001)$ & & $3.13(1.14-8.59)$ & \\
\hline Don't know & $1.74(0.94-3.23)$ & & $1.38(0.32-5.94)$ & & $2.12(1.04-4.31)$ & \\
\hline Tobacco use & $0.50(0.24-1.05)$ & 0.066 & $<0.001(<0.001-<0.001)$ & $<0.0001$ & $0.52(0.25-1.07)$ & 0.077 \\
\hline Alcohol use & $0.75(0.40-1.39)$ & 0.362 & $0.32(0.07-1.41)$ & 0.133 & $0.65(0.35-1.19)$ & 0.160 \\
\hline Longstanding use of street medications & $1.77(0.87-3.60)$ & 0.113 & Few events & & $1.17(0.52-2.63)$ & 0.713 \\
\hline Systolic blood pressure, mmHg & $1.01(1.00-1.02)$ & 0.018 & $1.02(0.99-1.05)$ & 0.158 & $1.01(1.00-1.02)$ & 0.002 \\
\hline Diastolic blood pressure, mmHg & $1.01(0.99-1.03)$ & 0.175 & $1.02(0.97-1.08)$ & 0.342 & $1.01(1.00-1.03)$ & 0.038 \\
\hline Any hypertension & $2.07(1.38-3.11)$ & 0.0004 & $2.85(0.65-12.45)$ & 0.163 & $2.19(1.47-3.25)$ & 0.0001 \\
\hline Body mass index $\geq 25 \mathrm{~kg} / \mathrm{m}^{2}$ & $1.34(0.89-2.02)$ & 0.157 & $1.55(0.35-6.83)$ & 0.564 & $1.22(0.84-1.78)$ & 0.288 \\
\hline Any diabetes & $2.43(1.15-5.16)$ & 0.021 & $3.88(0.75-20.19)$ & 0.107 & $2.74(1.26-5.98)$ & 0.011 \\
\hline
\end{tabular}

CKD Chronic kidney disease, GFR glomerular filtration rate (GFR), $95 \%$ Cl $95 \%$ confidence intervals

studies performed in SSA and low-to-middle income countries $[8,9,19-21]$. This result could be related to the higher prevalence and lower awareness of CKD and related risk factors observed in this population. Indeed, we found a high prevalence of CKD risk factors including diabetes, hypertension, and longstanding used of herbal and street medications which have been identified as predictors of CKD in this setting $[9,11,20]$. These results support the notion that Africans are at higher risk of CKD and confirm the high burden of CKD to be a worldwide phenomenon [3, 4, 22, 23]. However, variable CKD prevalence estimates have been published depending on the study design and setting, the target population characteristics, and the CKD definition and evaluation method [10-12, 24-26]. Compared to urban settings, CKD seems to be more prevalent in rural areas despite the lack of statistical difference as noticed in the metanalysis by Stanifer et al. [9]. The likely high prevalence observed in rural setting could be related to the high frequency of well-known clinical and sociodemographic risk factors for CKD occurrence and progression to ESRD [13].
In these apparently healthy populations, we observed that $2.5 \%$ of the participants had CKD stages G3-G4. Numerous previous studies have reported a much higher prevalence of decreased eGFR $(<60 \mathrm{ml} / \mathrm{min} /$ $1.73 \mathrm{~m}^{2}$ ) based on a single assessment of the kidney function $[8,12,19,21,24,26,27]$. The difference would tend to confirm that studies based upon a single timepoint assessment of kidney function overestimates the prevalence of CKD in population-based studies. However, some authors have also reported low prevalence of decreased eGFR based on single measurements, which could reflect true low prevalence, but also issues with the reliability of kidney function measurements including glomerular filtration rate estimation equations and the serum creatinine dosage method used $[6,10,11]$.

Based on quantitative estimation of albuminuria, we observed a high prevalence of albuminuria with rural predominance and rates similar to those observed by Varma et al. in India using the same method [19]. Most published studies have reported much higher prevalence of albuminuria similar to those observed in our study population based only on the first measurement $[7,8,12]$. The semi- 
quantitative dipstick method of albuminuria assessment without confirmation test, the bias in reading the results and the presence of transient proteinuria could explain this high prevalence. Nevertheless, some authors have also reported low prevalence of albuminuria on dipstick with prevalence ranging from 2.25 to $7.4 \%$, which could reflect true lower risk of albuminuria in their population as well as bias in reading the results $[10,11,25,27]$.

The reported high prevalence of CKD, stages G3-G4 and albuminuria in our study, driven essentially by hypertension, diabetes, obesity and longstanding used of herbal and street medications invite policy makers to undertake an array of actions to promote and sustain nephroprotection. Such actions could include the implementation of an integrated CKD prevention and care programmes in order to promote the screening of high-risk populations, patient education and creation of multidisciplinary care teams. The implementation of such programmes has been shown to significantly reduce mortality, incidence of end stage renal disease and dialysis, and dialysis related cost [20].

\section{Strengths and limitations}

The present study has some limitations including the non screening of participants for endemic infections conferring high risk of CKD such as HIV infection, hepatitis B and C viral infection; and the non-exhaustive assessment of socioeconomic status which has been shown to be associated with CKD $[9,21]$. Moreover, by conducting this study in only one geographical site, despite its cosmopolitan population, there is little opportunity of assessing the variations in the prevalence of CKD across the country. However, this study to our knowledge is the first to provide community-based data on the epidemiology of kidney disease in the country using the optimal approach to CKD screening [13]. The inclusion of participants from a cosmopolite health district including an urban and rural area likely captures the diversity of the national population. Another major strength of this study is the provision of a complete picture of the CKD and albuminuria prevalence as well as their determinants in this population presenting a high prevalence of common risk factors of CKD.

\section{Conclusion}

This study has revealed a high prevalence of CKD, stages G3-G4 and albuminuria in this setting, driven essentially by their commonest risk factors, and predominantly in rural area. These findings invite an array of actions to promote and sustain preventive measures to lower the risk of $\mathrm{CKD}$, promote early detection of the disease and implementation of measures to slow the progression to the terminal stage of the disease.

\section{Additional file}

Additional file 1: Table S1. The different clusters and corresponding health areas. (DOCX $15 \mathrm{~kb}$ )

\section{Abbreviations}

BMI: Body mass index; CG: Cockroft-Gault; CKD: Chronic kidney disease; CKDEPI: Chronic kidney disease epidemiology collaboration; DBP: Diastolic blood pressure; eGFR: Estimated glomerular filtration rate; MDRD: Modification of Diet in Renal Disease; SBP: Systolic blood pressure; SD: Standard deviation.

\section{Competing interests}

The authors declare that they have no competing interests.

\section{Authors' contributions}

FFK: Conception and design of the study, supervision of data collection, interpretation of data and drafting of the manuscript. DTM: Data collection and critical revision of the manuscript. MPH: Conception and design of the study and critical revision of the manuscript. JN: Supervision of data collection, interpretation of data and critical revision of the manuscript. APK: Data analysis and interpretation, and drafting of the manuscript. All authors read and approved the final manuscript.

\section{Acknowledgements}

We thank the Dschang health district community for participating in the study. We also thank the administrative and traditional leaders of this community for their support during the study as well as the biochemistry laboratory technicians of the Yaoundé University Teaching Hospital.

\section{Funding}

The authors declare that they have no funding source.

\section{Author details}

${ }^{1}$ Department of Internal Medicine and Specialties, Faculty of Medicine and Biomedical Sciences, University of Yaoundé 1, Yaoundé, Cameroon. ${ }^{2} \mathrm{Higher}$ Institute of Health Sciences, Bangangté, Cameroon. ${ }^{3}$ Department of Internal Medicine and Specialties, Faculty of Medicine and Pharmaceutical Sciences, University of Douala, Douala, Cameroon. ${ }^{4}$ South African Medical Research Council \& University of Cape Town, Cape Town, South Africa.

Received: 22 March 2015 Accepted: 16 July 2015

Published online: 30 July 2015

\section{References}

1. World Kidney Day. World kidney day: FAQS. Available from: http:// www.worldkidneyday.org/faqs (accessed date: 15th August 2014).

2. Lozano R, Naghavi M, Foreman K, Lim S, Shibuya K, Aboyans V, et al. Global and regional mortality from 235 causes of death for 20 age groups in 1990 and 2010: a systematic analysis for the Global Burden of Disease Study 2010. Lancet. 2012;380(9859):2095-128.

3. Naicker S. End-stage renal disease in sub-Saharan Africa. Ethn Dis. 2009;19 (1 Suppl 1):S1. -13-15.

4. Marshall SJ. Developing countries face double burden of disease. Bull World Health Organ. 2004;82(7):556.

5. Bamgboye EL. End-stage renal disease in sub-Saharan Africa. Ethn Dis. 2006;16(2 Suppl 2):S2. -5-9.

6. Eastwood JB, Kerry SM, Plange-Rhule J, Micah FB, Antwi S, Boa FG, et al. Assessment of GFR by four methods in adults in Ashanti, Ghana: the need for an eGFR equation for lean African populations. Nephrol Dial Transplant 2010;25(7):2178-87.

7. Sumaili EK, Nseka NM, Lepira FB, Krzesinski JM, Makulo JR, Bukabau JB, et al. Screening for proteinuria and chronic kidney disease risk factors in Kinshasa: a World Kidney Day 2007 study. Nephron Clin Pract. 2008;110(4):c220-8.

8. Sumaili EK, Krzesinski JM, Zinga CV, Cohen EP, Delanaye P, Munyanga SM, et al. Prevalence of chronic kidney disease in Kinshasa: results of a pilot study from the Democratic Republic of Congo. Nephrol Dial Transplant. 2009;24(1):117-22.

9. Stanifer JW, Jing B, Tolan S, Helmke N, Mukerjee R, Naicker S, et al. The epidemiology of chronic kidney disease in sub-Saharan Africa: a systematic review and meta-analysis. Lancet Glob Health. 2014;2(3):e174-81. 
10. Bukabau JB, Makulo JR, Pakasa NM, Cohen EP, Lepira FB, Kayembe PK, et al. Chronic kidney disease among high school students of Kinshasa. BMC Nephrol. 2012;13:24.

11. Seck SM, Doupa D, Gueye L, Ba I. Chronic kidney disease epidemiology in northern Senegal: a cross-sectional study. Iran J Kidney Dis. 2014;8(4):286-91.

12. Sumaili EK, Cohen EP, Zinga CV, Krzesinski JM, Pakasa NM, Nseka NM. High prevalence of undiagnosed chronic kidney disease among at-risk population in Kinshasa, the Democratic Republic of Congo. BMC Nephrol. 2009:10:18.

13. KVIGO Guidelines. Definition and classification. Kidney Int Suppl. 2013;3(1):19-62.

14. Chalmers J, MacMahon S, Mancia G, Whitworth J, Beilin L, Hansson L, et al. World Health Organization-International Society of Hypertension Guidelines for the management of hypertension. Guidelines sub-committee of the World Health Organization. Clin Exp Hypertens 1999. 1999;21(5-6):1009-60

15. Cockcroft DW, Gault MH. Prediction of creatinine clearance from serum creatinine. Nephron. 1976;16(1):31-41.

16. Levey AS, Coresh J, Greene T, Stevens LA, Zhang YL, Hendriksen S, et al. Using standardized serum creatinine values in the modification of diet in renal disease study equation for estimating glomerular filtration rate. Ann Intern Med. 2006;145(4):247-54.

17. Levey AS, Stevens LA, Schmid CH, Zhang YL, Castro 3rd AF, Feldman Hl, et al. A new equation to estimate glomerular filtration rate. Ann Intern Med. 2009:150(9):604-12.

18. Rule AD, Bailey KR, Schwartz GL, Khosla S, Lieske JC, Melton 3rd L. For estimating creatinine clearance measuring muscle mass gives better results than those based on demographics. Kidney Int. 2009;75(10):1071-8.

19. Varma PP, Raman DK, Ramakrishnan TS, Singh P, Varma A. Prevalence of early stages of chronic kidney disease in apparently healthy central government employees in India. Nephrol Dial Transplant. 2010;25(9):3011-7.

20. Hwang SJ, Tsai JC, Chen HC. Epidemiology, impact and preventive care of chronic kidney disease in Taiwan. Nephrology (Carlton). 2010;15 Suppl 2:3-9.

21. Amato D, Alvarez-Aguilar C, Castaneda-Limones R, Rodriguez E, Avila-Diaz $\mathrm{M}$, Arreola F, et al. Prevalence of chronic kidney disease in an urban Mexican population. Kidney Int Suppl. 2005;97:S11-7.

22. Iseki K. Chronic kidney disease in Japan from early predictions to current facts. Nephron Clin Pract. 2008;110(4):c268-72.

23. Coresh J, Selvin E, Stevens LA, Manzi J, Kusek JW, Eggers P, et al. Prevalence of chronic kidney disease in the United States. Jama. 2007:298(17):2038-47.

24. Rajapurkar MM, John GT, Kirpalani AL, Abraham G, Agarwal SK, Almeida AF, et al. What do we know about chronic kidney disease in India: first report of the Indian CKD registry. BMC Nephrol. 2012;13:10.

25. de Lima AO, Kesrouani S, Gomes RA, Cruz J, Mastroianni-Kirsztajn G. Population screening for chronic kidney disease: a survey involving 38,721 Brazilians. Nephrol Dial Transplant. 2012;27(3):iii135-8.

26. Matsha TE, Yako YY, Rensburg MA, Hassan MS, Kengne AP, Erasmus RT Chronic kidney diseases in mixed ancestry south African populations: prevalence, determinants and concordance between kidney function estimators. BMC Nephrol. 2013;14:75.

27. Singh NP, Ingle GK, Saini VK, Jami A, Beniwal P, Lal M, et al. Prevalence of low glomerular filtration rate, proteinuria and associated risk factors in North India using Cockcroft-Gault and Modification of Diet in Renal Disease equation: an observational, cross-sectional study. BMC Nephrol. 2009;10:4.

\section{Submit your next manuscript to BioMed Central and take full advantage of:}

- Convenient online submission

- Thorough peer review

- No space constraints or color figure charges

- Immediate publication on acceptance

- Inclusion in PubMed, CAS, Scopus and Google Scholar

- Research which is freely available for redistribution 